Peshawar Journal of Psychology and Behavioral Sciences, 2015, Vol. 1, No. 2, 99-114

\title{
Comparison of Single Child Family Adolescents and Adolescents with Number of Siblings
}

\section{Amara Iqbal' ${ }^{1}$ and S. Farhana Kazmi ${ }^{2}$}

\author{
Hazara University, Mansehra
}

\begin{abstract}
The aim of the present study was to ascertain the difference between adolescents belonging to only child family and adolescents belonging to number of siblings. To main objectives of the study were to examine that the difference between self esteem, quality of life and personality type of adolescents belonging to only child family and the association between the self esteem, quality of life and personality type of adolescents belonging to only child family. Population of the present study comprised of hundred $(\mathrm{N}=100)$ participants. The sample included fifty $(n=50)$ (only child) adolescent who is the only child of their biological parents and fifty $(n=50)$ adolescents having number of siblings studying in different schools, colleges and universities of Abbottabad, Mansehra, and Haripur. Urdu version of "Riffai Self esteem inventory", "World health organization quality of life questionnaire" and Eysenck personality questionnaires (2007) were used for data collection. t-test was used to analyze the data. Finding showed that that there is a difference between the scores of participants who were the single child of their parents and subject belonging to number of children family.
\end{abstract}

Keywords. Single child family, number of siblings, adolescents, selfesteem, quality of life, and types of personality,

Family is an important element of one's life. The size of the family directly affects the quality of life. The children of small family can easily fulfill necessary facilities and services available in proper manner, and also children of small family get nutritious food, seasonal clothes, and quality education. Less amount of family income is spent in fulfilling the basic needs of the small family. Parents also can easily undertake the responsibilities towards their children in the small family. Thus, the family size helps to maintain the quality of life (Anish, 2010).

\footnotetext{
${ }^{1}$ MS Scholar, Department of Psychology, Hazara University, Mansehra

${ }^{2}$ Assistant Professor, Department of Psychology, Hazara University, Mansehra
} 
Family size has an effect on our personalities and propensity and it's connected to several significant social factors, like race, traditions, educations, and income. Parent's qualification is one of the reasons has effect of smaller children better quality of life (Joshua, 2009). Family size stands for number of children in the family. More children mean that parental resources (money, time and attention) have to be spread more thinly. Family size is linked with many important social factors, such as traditions, schooling and riches (Hartshorne, 2010).

Roberts and Blanton (2001) reported that only child seeks everything either its good or bad for him. Only child wishes increase day by day and he doesn't care what he gains, profit or loss. Thus the only child becomes spoiled, self centered and greedy. When only child becomes a grownup person different prospects change his life style his parenting style, deepest personality traits are founded. They also surveyed that only child when he is in teenage were happy to create relationship with others and feel relaxed. The survey also suggested that when these only children reached at older age they were satisfied with their relationships and highly motivated to joining gathering and easy

Radwan (2014) described personality traits of the one child of their parents he has good qualities and he wants to utilize them but sometime he feels alone and receives disapproval from others he doesn't know how to behave and control the situation. Brilliant and qualified adults make impact on only child, it means that only children are social and they enjoy company of others. Only child have social skills they get pleasure from the companionship of others as well as seek pleasure with own self these personality qualities assist them to unite with other people, several only children are particularly conscious about critical situation and they don't know how to react.

Sager (2014) found following characteristics of only child like sibling rivalry makes for unhappy only child and being victims of bullying, having poorer social skills, they are more likely to divorce, they could be criminals, they get higher grades, they are not lonely at all, they are typically nicer than children with siblings.

Extroversion and introversion personality traits of only children ought to more involve in social situation because they need to be further estimation of personality traits (Koontz, 1989). Sulloway (1997) 
compared personality traits of varied siblings birth order and only children he concluded that elder are dominant, central are abandoned, last born are blemished, and finally only children are considered self centered and narcissistic.

Quality of life (QOL) is the universal well being of persons and society. Quality of life involved not only prosperity and employment but also the built atmosphere, bodily and psychological fitness, schooling, leisure, vacation and public belonging (Gregory \& Derek, 2009). Smaller family children feel that when they interact with other children they will have diseases and it shows inferiority complexes developed and their health and hygiene deteriorated (Strachan, 1989).

The term "self-esteem" is commonly used to refer to the assessment of people make about them. It includes position of satisfaction or dissatisfaction and the extent to which people feel admirable, competent, momentous, and effectual. Self esteem is usually measured the evaluative constituent of the self-concept, a broader demonstration of the self that includes cognitive and behavioral component (Garrety. K, 2003; Leary, 1999). Coopersmith's (1967) found that self-esteem was "the assessment which the individual construct and normally sustain with consider to himself/ herself".

Watkins and Astilla (1980) investigation only child self - esteem has varied result. Different studied have concluded high level of self esteem of three group of (first, last and only children). Further contemplation specified different kinds of self esteem were measured, like participant's age, parental and sibling assistance to the improvement of self esteem. Sack (2012) studied that dominant parents are perilous to their children's self-esteem. Children have ability to overcome challenges of all kinds and shows reliance that are admirable and it's not necessary they succeed always.

Trzesniewski (2006) found that children with low self esteem during teenage years having poor psychological and physical well-being, poor financial comforts, and huge level of unlawful or immoral acts. Cross sectional research suggests that Self esteem is linked with different personality types like adolescent with high self esteem are psychologically established, extrovert, hard worker, careful, pleasurable and share to skills or knowledge. Amplification of self esteem these different types also make clear personality differences. 
Houseknecht and Sharon (1982) conducted research on single children facing societal and behavioral problems. They concluded that only children are egoistic, self-centered, spoilt, they feel alone and neglect every day communication. One study shows that approximately $38 \%$ children, they bring up without siblings started having psychosocial problems and 54\% children have psychosomatic problems. And this study also identified that more risk factors of only children are psychosomatic complaints like recurrent bouts of abdominal pain, body dimorphic disorder, indigestion and hysterical fits.

Chandra (1983) studied at Quality of life, a broad and complex concept, appears to broadly include the following: satisfaction of emotional and psychological needs and of social aspirations; cultural and esthetic values; properly adjusted family life; provision of various social welfare services and amenities; satisfaction of essential needs like food, clothing, housing, and so forth; mental and physical health; and recreation. The association among family size and child wellbeing considered in many components like family income, family needs, food, health, housing, education, and recreation and it concluded that large family size leads to poverty in contrast to small family size greater likelihood of their children.

The purpose of the present research is to explore the relation between family design and aptitude. We examined the effects of two mechanism of family design: family size (number of children), and age spacing between repeated births. The effects of family design on aptitude have been of long-standing attention. With the prospects of family size most studies show a negative relation between family size and aptitude (Markus \& Zajoncs, 1977).

The proposed study was intended to investigate the effect of family size on self-esteem, quality of life and personality type of adolescents residing in Hazara division. As literature review indicates the quality of life, self-esteem and personality type are closely interlinked. Previous researchers have found family size correlates with self-esteem, quality of life and personality type of adolescents (e.g., Helseth \& Misvaer, 2009; Lewis, 2010; Demerica, 2010). 


\section{Method}

\section{Objectives}

1. To find out the difference between self esteem of adolescents belonging to only child family and family with number of children.

2. To find out the difference between quality of life of adolescents belonging to only child family and family with number of children.

3. To find out the difference between personality type of adolescents belonging to only child family and family with number of children.

\section{Hypotheses}

1. There will be significant difference between the scores of selfesteem among adolescents belonging to only child family and adolescents belonging to number of children family.

2. There will be significant difference between the scores of quality of life among adolescents belonging to only child family and adolescents belonging to number of children family.

3. There will be significant difference between the scores of personality type among adolescents belonging to only child family and adolescents belonging to number of children family.

\section{Operational Definition of Variables}

\section{Family size}

A group of people related by heredity, such as parents, children, and siblings. Family size is sometimes used to represent the total number of individuals comprising a family unit (Treas, 1981). In the present study family having single child is supposed to be small family size and family comprising of two or more children is supposed to be large family size.

\section{Self esteem}


Self esteem refers to a person's sense of worth and the extent to which a person values or likes himself (Blascovich \& Tomaka, 1991). A person secured high scores on self esteem scale has high self esteem and a person scores low on self esteem scale has low self esteem.

\section{Quality of life}

Quality of Life as persons observation of their situation in life in the context of the civilization and society systems in which they exist and in relation to their ambitions, prospects, principles and apprehension. It is a wide-ranging consciousness affected in a multifaceted way by the person's physical wellbeing, psychological condition, level of selfdetermination, social interaction, individual attitude and their affiliation to most important features of their environment (WHO, 1997). The high score on WHOQOL indicates higher quality of life and low scores indicates lower quality of life.

\section{Personality types}

A class of individuals with common characteristic or pattern of characteristics (physical/psychological) the three dimensions of neuroticism (stable vs. unstable) introversion-extroversion and Psychoticism combine to form a variety of personality characteristics. Extraverts are sociable and crave excitement, introverts are reserved, plan their actions and control their emotions. Neurotic/unstable tend to be anxious, worrying and moody, stables are emotionally calm, unreactive and unworried and the third trait dimension - Psychoticism e.g. lacking in empathy, cruel, a loner, aggressive (Eysenck, 1966). In the present research personality type are measured by three main dimensions of Eysenck personality questionnaires (jr) Urdu version (2007).

\section{Research Design}


Quantitative, cross - sectional based survey research design is employed for the present study.

\section{Sample}

The sample of present study is consisting of 100 respondents (only child $=50$, number of child $=50$ ) with age ranging from $11-19$ years were selected from Hazara division through purposive sampling.

Table 1

Frequency and percentages of demographics variable $(\mathrm{N}=100)$

\begin{tabular}{llll}
\hline Demographic & Group & F & \%age \\
\hline \multirow{2}{*}{ Gender } & Male & 59 & 59 \\
\multirow{2}{*}{ Age } & Female & 41 & 41 \\
& & & \\
Family size & $11-15$ & 40 & 40 \\
& $16-19$ & 60 & 60 \\
Place & Only children & 50 & 50 \\
& Number of & 50 & 50 \\
& children & & \\
& Abbottabad & 62 & 62 \\
& Haripur & 21 & 21 \\
& Mansehra & 17 & 17 \\
\hline
\end{tabular}

\section{Instruments}

\section{Self Esteem Scale}

The urdu version of Rifai self-esteem scale (1999) was used to measure the self-esteem of Adolescents. The urdu version is a selfadministered 29 items scale that measures self-esteem as uni-dimensional global self-esteem. The self esteem scale constitutes of four subscales (a) Self- acceptance (b) Self-competence (c) Social and physical Self- 
acceptance (d) Academic self competence. The respondents used a 5 point response format to indicate how often they feel about themselves ranging from 1 (strongly Disagree) to 5 (strongly Agree). Item no 1, 5,7 $, 8,11,13,16,19,21,25,28$ are negatively scored items. The Alpha reliability as determined by Rifai (1999) is .83. The higher scores indicate higher level of self esteem and lower level indicates low level of self esteem. The reliability of self esteem scale for present scale is .60.

\section{World Health Organization Quality Of Life Questionnaire (WHO-QOL-BREIF)}

It was developed by Power (2003) and urdu translated by Khan, Akhtar, Ayub , Alam, and Laghari (2003) used to measure the quality of lifeof Adolescent. The urdu version is a self administered 26 items scale that measures quality of life. The scale was translated and adapted in urdu by Khan, Akhtar, Ayub, Alam , and Laghari (2003). The WHOQOL brief scale constitutes of five subscales (a) Physical Functioning (b) Psychological Functioning (c) Social Dimension (d) Environment (e) Perception of quality of life and health. The respondents used a 5 point response format to indicate how often they feel about themselves ranging from 1 (strongly Disagree) to 5 (strongly Agree). There is no cut off scores in the scale therefore high score indicates high quality of life and vice versa. The Alpha reliability as determined by Shahbaz (2010) is .68 to .77, Mir (2008) is .89, Saleem (2003) is .80 and Batool (2010) is 88. The higher scores indicate higher level of quality of life and lower level indicates low level of quality of life. The reliability of quality of life scale for present scale is .80 .

\section{Eysenck Personality Questionnaire (EPQ)}

It was developed by Eysenck (1975) and urdu translated by Naqvi (2007) was used to measure the personality traits of Adolescent. The urdu version is a self administered 81 items scale that measures personality traits. The scale was translated and adapted in urdu by Naqvi (2007). The Eysenck Personality Questionnaire constitutes of four subscales (a) Extroversion- Introversion (b) Neuroticism(c) Psychoticism

(d) Lie. The respondents used a 2 point response format to indicate how 
often they feel about themselves ranging from 1 (yes) and 2(No). The Alpha reliability as determined by Naqvi (2007) is .90 The higher scores indicates higher level of personality traits and lower level indicates low level of personality traits. The reliability of Eysenck Personality Questionnaire for present scale is 70 .

\section{Procedure}

For the present study 100 hundred participants were approached from different schools and colleges and universities of Hazara division. Self esteem, quality of life and personality scales are used in individual setting. Informed consent of the participant taken and they are assured of confidentiality. Questionnaire are given and taken back from participant after completion. After collecting the data it was put into SPSS for statistical analysis. Correlations are applied to find out the relationship between family size with self esteem, quality of life and personality type of adolescents. The result is shown in tables.

\section{Results}

Table 2

Summary of Intercorrelations, Means, and Standard Deviations for Scores on the SES, QOL, and EPQ.

\begin{tabular}{ccccccc}
\hline & Measure & 1 & 2 & 3 & $\mathrm{M}$ & $\mathrm{SD}$ \\
\hline 1. & SES & - & .018 & .010 & 94.9 & 11.12 \\
2. & QOL & -.006 & - & $.383^{* *}$ & 94.3 & 8.29 \\
3. & EPQ & .171 & .056 & - & 20.0 & $4 \mathrm{w} .0$ \\
M & & 94.7 & 88.0 & 17.6 & & \\
SD & & & & & & \\
\hline
\end{tabular}


Table 3

Difference Between Single Child and Adolescents with Number of Siblings Sub Scale of Eysenck Pesronality Questionnaire $(\mathrm{N}=200)$

\begin{tabular}{|c|c|c|c|c|c|c|c|c|c|}
\hline \multirow{3}{*}{ Variables } & \multicolumn{2}{|c|}{$\begin{array}{l}\text { Single Child } \\
(\mathrm{n}=100)\end{array}$} & \multicolumn{2}{|c|}{$\begin{array}{c}>\text { One Child } \\
(\mathrm{n}=100)\end{array}$} & \multirow{3}{*}{$\mathrm{t}(198)$} & \multirow{3}{*}{$\mathrm{p}$} & & & \multirow{3}{*}{$\begin{array}{c}\text { Cohen's } \\
\text { d }\end{array}$} \\
\hline & \multirow{2}{*}{ M } & \multirow{2}{*}{ SD } & \multirow{2}{*}{ M } & \multirow{2}{*}{ SD } & & & \multicolumn{2}{|c|}{ CI 95\% } & \\
\hline & & & & & & & LL & UL & \\
\hline Ext.In & 17.20 & 3.40 & 15.76 & 3.37 & 2.12 & .03 & .09 & 2.78 & 0.42 \\
\hline Psycho & 5.50 & 3.46 & 4.96 & 2.64 & .876 & .38 & -.68 & 1.76 & 0.17 \\
\hline Neurtc & 9.70 & 3.31 & 9.28 & 3.83 & .56 & .56 & -1.00 & 1.84 & 0.11 \\
\hline Lie & 13.50 & 3.78 & 11.50 & 4.09 & 2.53 & .01 & .43 & 3.56 & 0.50 \\
\hline
\end{tabular}

Table 3 shows independent sample t-test of scores of Eysenck personality questionnaire (EPQ) result shows significant difference between the scores of adolescents belonging to single child and number of children families. Single child $(M=17.20, S D=3.40)$ scored higher on Extrovert and Introvert than adolescents belonging to number of children family $(\mathrm{M}=15.76, \mathrm{SD}=3.37)$, significant $\mathrm{t}(198)=2.12$, with mean difference $1.44, \mathrm{p}<.03 ; \mathrm{d}=.42$, CI 95\% $[.09,-2.78]$. The effect size for this analysis was exceeding Cohen's (1988) convention for moderate effect (.30-.80).

Table 4

Difference Between Single Child and Adolescents with Number of Siblings on Sub Scales of Self Esteem $(\mathrm{N}=200)$

\begin{tabular}{|c|c|c|c|c|c|c|c|c|c|}
\hline \multirow{3}{*}{ Variables } & \multicolumn{2}{|c|}{$\begin{array}{c}\text { Single Child } \\
(\mathrm{n}=100)\end{array}$} & \multicolumn{2}{|c|}{$\begin{array}{c}>\text { One Child } \\
(\mathrm{n}=100)\end{array}$} & \multirow{3}{*}{$\mathrm{t}(198)$} & \multirow{3}{*}{$\mathrm{p}$} & & & \multirow{3}{*}{$\begin{array}{c}\text { Cohen's } \\
\text { d }\end{array}$} \\
\hline & \multirow{2}{*}{ M } & \multirow{2}{*}{$\mathrm{SD}$} & \multirow{2}{*}{ M } & \multirow{2}{*}{ SD } & & & \multicolumn{2}{|c|}{ CI 95\% } & \\
\hline & & & & & & & LL & UL & \\
\hline SA & 20.96 & 7.49 & 25.82 & 8.40 & -3.05 & .003 & -8.01 & -1.70 & 0.61 \\
\hline $\mathrm{SC}$ & 25.14 & 3.81 & 22.98 & 4.58 & 2.55 & .012 & .48 & 3.83 & 0.51 \\
\hline SPA & 29.10 & 4.82 & 27.86 & 4.17 & 1.37 & .172 & -.55 & 3.03 & 0.27 \\
\hline ASC & 18.70 & 2.98 & 16.44 & 3.29 & 3.59 & .001 & 1.01 & 3.50 & 0.72 \\
\hline
\end{tabular}

Note: SA: Self Acceptance, SC:Self Competence, SPA: Social Physical Acceptance, ASC: Academic Self Acceptance 
Table 4 shows independent sample t-test of scores of Self Esteem result shows significant difference between the scores of adolescents belonging to single child and number of children. Single child $(\mathrm{M}=25.82, \mathrm{SD}=8.400)$ scored higher than number of children family $(M=20.96, S D=7.49)$, significant $t(198)=-3.053$, with mean difference 4.86, $\mathrm{p}<.003 ; \mathrm{d}=.61, \mathrm{CI} 95 \%$ [-8.019, -1.701]. The effect size for this analysis was exceeding Cohen's (1988) convention for moderate effect (.30-.80).

Table 5

Difference Between Single Child and Adolescents with Number of Siblings Sub Scales of Quality of Life (WHOQO) (N=200)

\begin{tabular}{|c|c|c|c|c|c|c|c|c|c|}
\hline & \multicolumn{2}{|c|}{$\begin{array}{l}\text { Single Child } \\
(\mathrm{n}=100)\end{array}$} & \multicolumn{2}{|c|}{$\begin{array}{l}>\text { One Child } \\
(\mathrm{n}=100)\end{array}$} & \multirow{3}{*}{$\mathrm{t}(198)$} & \multirow{3}{*}{$\mathrm{P}$} & & & \multirow{3}{*}{$\begin{array}{c}\text { Cohen's } \\
\text { d }\end{array}$} \\
\hline & \multirow[t]{2}{*}{$M$} & \multirow[t]{2}{*}{ SD } & \multirow[t]{2}{*}{$\mathrm{M}$} & \multirow[t]{2}{*}{ SD } & & & \multicolumn{2}{|c|}{ CI 95\% } & \\
\hline & & & & & & & LL & UL & \\
\hline $\mathrm{PhF}$ & 24.16 & 2.22 & 22.04 & 4.59 & 2.93 & .004 & .68 & 3.55 & 0.58 \\
\hline PsyF & 21.46 & 2.77 & 20.40 & 2.81 & 1.89 & .061 & -.04 & 2.16 & 0.37 \\
\hline SF & 12.08 & 1.75 & 11.34 & 2.70 & 1.62 & .108 & -.14 & 1.64 & 0.32 \\
\hline Envir & 30.30 & 5.28 & 27.78 & 4.95 & 2.46 & .016 & .48 & 4.55 & 0.49 \\
\hline QOL & 6.38 & .987 & 6.50 & 1.11 & -.57 & .569 & -.53 & .29 & 0.11 \\
\hline
\end{tabular}

Note: PhF: Physical Functioning, PsyF: Psychological Functioning, SF: Social Functioning, Envir: Environment, QOL: Quality of Life and Health

Table 5 shows independent sample t-test of scores of World Health Organization Quality Of Life Questionnaire (WHO-QOL-BREIF) result shows significant difference between the scores of adolescents belonging to single child and number of children families and Single child $(\mathrm{M}=24.16, \mathrm{SD}=2.11)$ scored higher on sub scale of physical functioning than adolescents belonging to number of children family $(\mathrm{M}=22.04, \mathrm{SD}=4.59)$, significant $\mathrm{t}(198)=2.93$, with mean difference 2.12, $\mathrm{p}<.004 ; \mathrm{d}=.58$, CI 95\% [.68, 3.55]. The effect size for this analysis was exceeding Cohen's (1988) convention for moderate effect (.30-.80).

\section{Discussion}

The findings of the present study are in line with the findings of to the study of Radwan (2014) described personality traits of the one 
child of their parents he has good qualities and he wants to utilize them but sometime he feels alone and receives disapproval from others he doesn't know how to behave and control the situation. Brilliant and qualified adults make impact on only child, it means that only children are social and they enjoy company of others. Only child have social skills they get pleasure from the companionship of others as well as seek pleasure with own self these personality qualities assist them to unite with other people, several only children are particularly conscious about critical situation and they don't know how to react.

Quality of life (QOL) is the universal well being of persons and society. Quality of life involved not only prosperity and employment but also the built atmosphere, bodily and psychological fitness, schooling, leisure, vacation and public belonging(Gregory \& Derek, 2009). Smaller family children feel that when they interact with other children they will have diseases and it shows inferiority complexes developed and their health and hygiene deteriorated (Strachan, 1989).

Rosenzweig and Zhang (2009) examined impact on quality of life of only children and the number of children. Finding suggested the children who have siblings have worse quality of life like poor academic achievement, low grades in colleges, poorer sanitation as compared to only children because their parents have limited resources low income that why number of children have poor quality of life.

Extroversion and introversion personality traits of only children ought to more involve in social situation because they need to be further estimation of personality traits (Koontz, 1989). Sulloway (1997) compared personality traits of varied siblings birth order and only children he concluded that elder are dominant, central are abandoned, last born are blemished, and finally only children are considered self centered and narcissistic.

Siribaddana (2012) conducted research on only one child personality traits and children who have siblings. There are three personality types described like normal, impetuous and first born child. He believed that only children have both positive and negative qualities, competent, making decision, organizational skills and regular participant to different events, educational performance, and good memory is a 
positive trait. Selfishness, highly susceptible and inability to bear criticism of others are negative traits of only children.

Watkins and Astilla (1980) investigation only child self - esteem has varied result. Different studied have concluded high level of self esteem of three group of (first, last and only children). Further contemplation specified different kind of self esteem were measured, like participant's age, parental and sibling assistance to the improvement of self esteem.

Kennedy (2011) also agreed that the positive relationship between personality traits of only children and study revealed that only children are extrovert and conscientious as well as high self esteem. Franchesca (2010) examined the significant relationship between only child and personality type or super traits introversion - extroversion, Agreeableness, Conscientiousness, Neuroticism and lie.

Makaremi (1992) studied the effects of only children on Eysenck four personality dimensions Extroversion- Introversion, Neuroticism, Psychoticism and Lie and concluded that there is significant relationship between only children, number of children and four personality dimensions of Eysenck. Additionally Goudreau (2013) agreed the significant relationship between only child and personality type conscientious, agreeable and extroverted.

Edelbrock, Rende, Plomin, and Thompson (2006) numerous researchers have recognized menace factors that hamper strong selfesteem increase in children. Menace factors are effects to the number of children, relatives, or society that put children in hazard of experiencing things that spoil them or smash up their aptitude to feel superior about themselves and their abilities. Parents became aware to risk factors and these factors protect their children.

\section{Conclusion}

The present study was a correlational study based on Alder theory and Resource dilution model, through this study it was concluded that only child family has low level of self esteem. It was identified that the non significant correlation between family size and quality of life among the adolescents who belongs to only child family and number of children family. It was also concluded that adolescents belonging to 
number of children family have poor quality of life due to poor physical health, sickness, poor-quality schooling and nutrition. Further it was also identified that the relationship between family size and personality type of adolescents who belongs to only child family and number of children family .It was also concluded that there were positive relationship between quality of life and personality type of adolescents belonging to only child family.

\section{References}

Anish (2010).Role of family size for maintaining quality of life. Education Sansar. Retrieved from http://www.educationsansars.blogspot.com/2010/05/role-offamily-size-for-maintaining.html

Batool, N. (2010). Lack of spiritual wellness and quality of life as predictors of delinquent tendencies among adolescents. M.Sc dissertation. Unpublished. National Institute of Psychology, Quaid-e-Azam University, Islamabad.

Chandra, R. (1983). Family size and quality of life. Knowledge for Health, 10(1), 4-8. Retrieved from http://www.popline.org/node/393562\#sthash.1OIwz8k0.meNxBb Qq.dpuf

Coopersmith, S. (1967).The Antecedents of Self-esteem. Retrieved from http://wat2146.ucr.edu/Papers/02b.pdf

Eysenck, H. J., \& Eysenck, S. B. G. (1975). Manual of the Eysenck Personality Questionnaire. London: Hodder and Stoughton.

Eysenck, H. J. (1966). Personality and experimental psychology. Bulletin of the British Psychological Society. Retrieved from http://www.simplypsychology.org/personality-theories.html

Edelbrock, C., Rende, R., Plomin, R., \& Thompson, L. A. (2006). A twin study of competence and problem behavior in childhood and early adolescence. Journal of Child psychology and psychiatry, 36(5), 775-785.doi: 10.1111/j.1469-7610.1995.tb01328.x

Gregory \& Derek (June 2009).Quality of Life. Dictionary of Human Geography (5). Oxford: Wiley-Blackwell. ISBN 978-1-40513287-9. 
Goudreau, J. (2013). Here's why only children are more successful: Business Insider Inc. Retrieved from http://www.businessinsider.com/heres-why-only-children-aremore-successful-2013-11\#ixzz3ZwClMyHs

Garrety, K. (2003). The use of personality typing in organizational change: Discourse, emotions and the reflexive subject. Human Relations, $56 \quad$ (2), 211- 235.Retrieved from http://www.researchgate.net/profile/N_Martins2/publication/477 39553_The_relationship_between_personality_preferences_selfesteem_and_emotional_competence/links/5469ab680cf2397f782 d7d5e.pdf

Houseknecht., \& Sharon, K. (1982). Childlessness and the one child family.Journal of Family Issues, (3), 419-593. Retrieved from http://www.ericdigests.org/pre-921/child.htm

Helseth, S., \& Misvaer, N. (2009).Adolescents' perceptions of quality of life.Journal of Clinical Nursing, 19, 14551462.doi:10.1111/j.1365-2702.2009.03069.x

Hartshorne, J. k. (2010). How Birth Order Affects Your Personality. Scientific American. Retrieved from http://www.scientificamerican.com/article.cfm?id=ruled-bybirth-order

Joshua, k. H. (2009).How Birth Order Affects Your Personality. Retrieved from http://www.scientificamerican.com/article/ruled-by-birth-order/

Koontz, K. (February 1989). Just me. Health, 21, 38-39. Retrieved from http://www.personalityresearch.org/papers/eischens2.html

Kennedy, E. (2011, December 8). Don't pity us, life's so much better as an only child Mail online. Retrieved fromhttp://www.dailymail.co.uk/femail/article-2071335/Onlybest-Why-children-happier-siblings.html

Makaremi, A. (1992). Birth order, neuroticism, and psychoticism among iranian children. Psychological Reports, 71, 919-922. doi: 10.2466/pr0.1992.71.3.919

Markus, G. B., \& Zajonc, R. B. (1977). Family configuration and intellectual development: A simulation. Behavioral Science, 22, $137-142$. 
Naqvi, I. (2007). Patterns of delinquency and personality traits of adolescence in child labor. Unpublished M.phil dissertation. National Institute of Psychology, Quaid-e-Azam University, Islamabad

Rifai, H. S., Borden, R. C., Wilson, J. T., \& Ward, C. (1999). Intrinsic bioattenuation for subsurface restoration, Intrinsic Psychological Assessment. 30, 261-275

Radwan, M. R. (2014). Only child personality traits. Birth Order and personality. Retrieved from http://www.2knowmyself.com/only_child_personality_traits

Roberts, L.C., \& Blanton, P.W. (2001). I always knew mom and dad loved me best: Experiences of only children. The Journal of Individual Psychology, 57, 125-140.

Rosenberg, B.G., \& Hyde, J.S. (1992). The Only Child: Is There Only One Kind of Only? The Journal of Genetic Psychology, 154(2), 269-282.

Rosenzweig, M. R. and Zhang, J. (2009) Do Population Control Policies Induce More Human Capital Investment? Twins, Birthweight, and China's 'One Child' Policy.Review of Economic Studies, 76, pp. 1149-1174.

Shahbaz, K. (2012). Relationship between spiritual well-being and Quality of Life among chronically ill individuals. M.Sc dissertation. Unpublished. National Institute of Psychology, Quaid-e-Azam University, Islamabad

Strachan, D. P (1989).Hay fever, hygiene, and household size. BMJ,229 (6710), 1259-1260. ISSN 0959-8138.

Sager, j. (2014). 8 Surprising Scientific Facts About Only Children: CMI Marketing Inc.

Sulloway, F. J. (September 1997).Birth order and personality. Harvard Mental Health Letter, 14,5-7.Retrieved fromhttp://www.personalityresearch.org/papers/eischens $2 . h t m l$

Siribaddana, P. (2012). Personality Traits of the only Child. Retrieved from http://www.sciences360.com/index.php/personality-traitsof-the-only-child-3045/

Trzesniewski, K. H. (2006). Low self-esteem during adolescence predicts poor health, criminal behavior, and limited economic prospects 
Comparison of Single Child Family Adolescents and Adolescents with ........

during adulthood. Developmental Psychology, 42(2), 381390. Retrieved from http://dx.doi.org/10.1037/00121649.42.2.381

Watkins, D., \& Astilla. (1980). Birth order, family size, and self-esteem.

The Journal of Genetic Psychology,137(2). Retrieved from http://www.sciencedirect.com/science/article/pii/S000187910200 0428 